\title{
Frequency of anemia in chronic psychiatry patients
}

This article was published in the following Dove Press journal:

Neuropsychiatric Disease and Treatment

22 October 2015

Number of times this article has been viewed

\author{
Sevda Korkmaz' \\ Sevler Yıldız' \\ Tuba Korucu' \\ Burcu Gundogan' \\ Zehra Emine Sunbul' \\ Hasan Korkmaz ${ }^{2}$ \\ Murad Atmaca' \\ 'Department of Psychiatry, \\ ${ }^{2}$ Department of Cardiology, Faculty \\ of Medicine, Fırat University, Elazıg, \\ Turkey
}

Purpose: Anemia could cause psychiatric symptoms such as cognitive function disorders and depression or could deteriorate an existing psychiatric condition when it is untreated. The objective of this study is to scrutinize the frequency of anemia in chronic psychiatric patients and the clinical and sociodemographic factors that could affect this frequency.

Methods: All inpatients in our clinic who satisfied the study criteria and received treatment between April 2014 and April 2015 were included in this cross-sectional study. Sociodemographic data for 378 patients included in the study and hemoglobin $(\mathrm{Hb})$ and hematocrit values observed during their admission to the hospital were recorded in the forms. Male patients with an $\mathrm{Hb}$ level of $<13 \mathrm{~g} / \mathrm{dL}$ and nonpregnant female patients with an $\mathrm{Hb}$ level of $<12 \mathrm{~g} / \mathrm{dL}$ were considered as anemic.

Findings: Axis 1 diagnoses demonstrated that 172 patients had depressive disorder, 51 patients had bipolar disorder, 54 patients had psychotic disorder, 33 patients had conversion disorder, 19 patients had obsessive-compulsive disorder, 25 patients had generalized anxiety disorder, and 24 patients had other psychiatric conditions. It was also determined that $25.4 \%$ of the patients suffered from anemia. Thirty-five percent of females and 10\% of males were considered as anemic. The frequency of anemia was the highest among psychotic disorder patients (35\%), followed by generalized anxiety disorder patients (32\%), and obsessive-compulsive disorder patients $(26 \%)$. Anemia was diagnosed in $22 \%$ of depressive disorder patients, $25 \%$ of bipolar disorder patients, and $24 \%$ of conversion disorder patients.

Results: The prevalence of anemia among chronic psychiatry patients is more frequent than the general population. Thus, the study concluded that it would be beneficial to consider the physical symptoms and to conduct the required examinations to determine anemia among this patient group

Keywords: anemia, hemoglobin, physical disease

\section{Introduction}

Anemia is a significant public health issue that affects a great number of people in developed and developing countries. Anemia is defined as the fall of hemoglobin $(\mathrm{Hb})$ concentration in blood below the normal level, which is determined by age and sex. ${ }^{1}$ World Health Organization determined that when the $\mathrm{Hb}$ value is $<13 \mathrm{~g} / \mathrm{dL}$ in an adult male and $<12 \mathrm{~g} / \mathrm{dL}$ in a nonpregnant female, the individual is considered as anemic. ${ }^{2}$ Several factors, such as insufficient erythrocyte production in bone marrow, nutrition disorders, blood loss, and decrease in iron absorption, could cause anemia. However, age, sex, race, socioeconomic status, the altitude of the habitat, posture, and changes in plasma volume could result in specific changes in hematocrit values. ${ }^{3}$ Anemia, when untreated, could cause physical symptoms, such as exhaustion, fatigue, and palpitation, and psychiatric symptoms, such as cognitive function disorders and depression. Anemia also could accompany several psychiatric diseases. This coexistence could cause certain complications or an increase in the severity of the preexisting condition in the patients. The relationship between anemia and psychiatric diseases is known for a long period of time. ${ }^{4-8}$ However, there are only a limited number of studies
Correspondence: Sevda Korkmaz Department of Psychiatry, Faculty of Medicine, Firat University, 23।I9 Merkez/ Elazığ, Turkey

Tel +905053510730

Fax +904242388096

Emailskorkmaz23@hotmail.com 
investigating $\mathrm{Hb}$ values, an indicator of anemia, among chronic psychiatric patients. ${ }^{9}$ Also, none of these studies scrutinized the relationship between anemia and psychiatric diagnosis and clinical and sociodemographic data that could affect this very relationship. Thus, this study aims to examine the frequency of anemia among chronic psychiatric patients based on their diagnoses and clinical and sociodemographic data, which could affect this frequency.

\section{Methodology}

All inpatients in our clinic who satisfied the study criteria and received treatment between April 2014 and April 2015 were included in this cross-sectional study. Upon the approval of the Firat University ethics committee, all inpatients in Firat University Psychiatry Clinic diagnosed with any psychiatric condition based on DSM 4-TR ${ }^{10}$ diagnostic criteria and over the age of 18 years provided written informed patient consent and were included in the study. Patients with a significant physical pathology or disease that could affect the distribution of existing psychological symptoms or those with a preexisting blood disease other than anemia were excluded from the study. $\mathrm{Hb}$ values were examined by ADVIA 2120i (Siemens Diagnostics, Tarrytown, NY, USA) equipment on the full blood samples taken from the patients in $2 \mathrm{~mL}$ complete blood count cartridges. Males with an $\mathrm{Hb}$ level of $<13 \mathrm{~g} / \mathrm{dL}$ and nonpregnant females with an $\mathrm{Hb}$ level of $<12 \mathrm{~g} / \mathrm{dL}$ were considered as anemic. Medical histories, general medical conditions, profiles, and family histories of the patients taken from their clinical files and sociodemographic data, such as age, sex, and educational background, were recorded in the forms designed by the author of this study. Hematological parameters such as $\mathrm{Hb}$, hematocrit, erythrocytary mean, corpuscular volume, and erythrocyte range, which were indicated during admission, and biochemical parameters such as urea, keratin, free T3 hormone, free T4 hormone, and thyroid-stimulating hormone were also recorded in the forms.

\section{Statistical method}

Existing data were examined along with a literature review. SPSS for Windows 21.0 software (Chicago, IL, USA) was used for data analysis. Student's $t$-test was conducted for paired comparisons, and chi-square test was used for categorical comparisons; both tests were available in the aforementioned software.

\section{Findings}

The study included all inpatients who fitted the study criteria and were treated in our clinic during the last 1-year period.
Based on Axis 1 diagnosis, 172 patients were diagnosed with depressive disorder, 51 patients were diagnosed with bipolar disorder, 54 patients were diagnosed with psychotic disorder, 33 patients were diagnosed with conversion disorder, 19 patients were diagnosed with obsessive-compulsive disorder, 25 patients were diagnosed with generalized anxiety disorder, and 24 patients were diagnosed with other psychiatric conditions. One hundred and forty-nine (39.4\%) patients were male, and 229 (60.6\%) patients were female. Patients' mean age was determined as $41.15 \pm 15.5$ (41 \pm 16 among males and $41 \pm 14$ among females; $P=0.927$ ). Sociodemographic characteristics of the study group are presented in Table 1. Anemia was indicated in $25.4 \%$ of the patients who participated in the study. Table 2 demonstrates the hematological and biochemical parameters for the study group. Anemia was identified in $35 \%$ of the psychotic disorder patients, $22 \%$ of the depressive disorder patients, and $25 \%$ of the bipolar disorder patients (Table 3 ). Thirtyfive percent of females and $10 \%$ of males were considered as anemic. The difference of this rate between males and females was statistically significant $(P<0.001)$. Hematological parameters based on sex are presented in Table 4 . Table 5 shows the mean $\mathrm{Hb}$ values based on age.

As a result of the analysis conducted by dividing the patients into groups of anemic patients and nonanemic patients, it was determined that $93 \%$ of the anemic patients were previously treated in an institution as inpatients. It was found that 29 individuals $(32 \%)$ in the anemic group had low-income levels. Fifty-five individuals $(60 \%)$ in the anemic group had an organic disease: nine of them had previous anemia history, and one of them had blood disease

Table I Sociodemographic characteristics of patients

\begin{tabular}{lll}
\hline $\mathbf{N}=\mathbf{3 7 8}$ & $\mathbf{N}$ & $\%$ \\
\hline Anemia & 96 & 25.4 \\
Sex (male) & 149 & 39.4 \\
Occupation (unemployed) & $26 \mathrm{I}$ & 69 \\
Low income & 119 & 31.5 \\
Illiterate & 57 & 15.1 \\
Married & 232 & 61.4 \\
Organic disease & 170 & 45 \\
Blood disease & 10 & 2.6 \\
Blood disease in family & 5 & 1.3 \\
Use of alcohol & 30 & 8 \\
Substance abuse & 4 & 1 \\
Smoking & 169 & 44.7 \\
Radiation history & 25 & 6.6 \\
Psychiatric drug use & 283 & 75 \\
Other drug use & 109 & 28.8 \\
First application & 16 & 4.2 \\
\hline
\end{tabular}


Table 2 Hematological and biochemical parameters of patients

\begin{tabular}{lll}
\hline $\mathbf{N}=\mathbf{3 7 8}$ & Mean & Standard deviation \\
\hline Age $($ years $)$ & 41.15 & 15.5 \\
Hb $(\mathrm{g} / \mathrm{dL})$ & $11.5 \mathrm{I}$ & 1.5 \\
Htc $(\%)$ & 34.25 & 3.26 \\
RDW $(\%)$ & 17.73 & 2.05 \\
MCV $(\mathrm{fL})$ & 74.78 & 10.87 \\
TSH $(\mu \mathrm{lU} / \mathrm{mL})$ & 2.83 & 3.62 \\
sT3 $(\mathrm{ng} / \mathrm{dL})$ & 1.82 & 2.32 \\
sT4 $(\mu \mathrm{g} / \mathrm{dL})$ & 1.4 & 1.33 \\
Urea $(\mathrm{mg} / \mathrm{dL})$ & 62.53 & 13.49 \\
RBC $\left(I 0^{6} / \mathrm{mm}^{3}\right)$ & 4.15 & 0.41 \\
Creatine $(\mathrm{mg} / \mathrm{dL})$ & 0.53 & 0.22 \\
\hline
\end{tabular}

Abbreviations: $\mathrm{Hb}$, hemoglobin; $\mathrm{Htc}$, hematocrit; $\mathrm{RDW}$, red blood cell distribution width; MCV, mean corpuscular volume; TSH, thyroid-stimulating hormone; sT3, free T3 hormone; sT4, free T4 hormone; RBC, red blood cells.

history in the family. Among the anemic patients, 67 (73\%) patients were on psychiatric drugs during the previous month of study, while $33(36 \%)$ patients were on nonpsychiatric drugs. Nine $(10 \%)$ anemic patients reported that they were exposed to radiation during the previous month of study. Forty-eight $(60 \%)$ female anemic patients stated that their menstrual cycles were regular.

\section{Discussion}

It was determined that $25.4 \%$ of the psychiatric patients also had anemia in the study. In a different study, which indicated the frequency of physical diseases among psychiatric inpatients, it was determined that $38 \%$ of the patients had at least one or more conditions on different systems. The same study indicated anemia in $12.2 \%$ of psychiatric patients. ${ }^{11}$ In another study where 6,688 inpatients in a psychiatric hospital were investigated, the same ratio was found as $6 \%{ }^{12}$ Anemia is seen predominantly in individuals with poor socioeconomic backgrounds, who have little access to the center and have difficulties in expressing physical symptoms. Thus, it is inevitable that the rate of anemia among psychiatric patients would be higher than the general population. However, the findings of this study were observed to be higher than the results of other studies in the literature. Our hospital predominantly serves a patient population that demonstrates severe symptoms, resistant to treatment, and intake of additional drugs due to other diagnoses. Among our patients, it could be possible that high frequency of drug use in high doses could have increased hematological side effects that develop due to drug use, and thus increasing the prevalence of anemia. Also intervening organic conditions could have increased the prevalence of anemia types, such as chronic disease anemia.

It is known that among women of reproductive age who experience blood loss due to menstrual bleeding, anemia is more frequent. In this study, $35 \%$ of females and $10 \%$ of males were determined as anemic. Although it varies based on the age group and domicile, anemia prevalence is generally reported as $28 \%$ among females and $10.4 \%$ among males in the literature. ${ }^{13}$ Although the mean anemia prevalence among males in the study was parallel to the findings in the literature, the anemia rates among females were higher than the rates reported in the literature.

The study findings demonstrated that anemia frequency was the highest (35\%) among the psychotic disorder patients based on diagnostic groups. This ratio was $40 \%$ among panic disorder patients. However, since there were only five participating panic disorder patients in the study, that finding could be misleading. In the literature, one study reported that $4.5 \%$ of schizophrenia patients also suffered anemia, and another study reported that $2.8 \%$ of anemic patients also suffered schizophrenia. ${ }^{14,15}$ The findings of this study reflected quite higher figures when compared to the findings reported in other studies in the literature. Psychotic disorder patients face negative living conditions where they could not express themselves and could not even sustain their basic needs of nourishment and accommodation. Since there are

Table 3 Comparison of patients' hematological parameters based on diagnoses

\begin{tabular}{|c|c|c|c|c|c|c|c|c|c|c|c|}
\hline $\mathbf{N}=378$ & $\begin{array}{l}\text { Dep d, } \\
\mathrm{n}=172\end{array}$ & $\begin{array}{l}\text { Bip d, } \\
n=5 \text { I }\end{array}$ & $\begin{array}{l}\text { Psyc, } \\
\mathrm{n}=54\end{array}$ & $\begin{array}{l}\text { Conv, } \\
n=33\end{array}$ & $\begin{array}{l}\text { OCD, } \\
n=19\end{array}$ & $\begin{array}{l}\text { Gad, } \\
n=25\end{array}$ & $\begin{array}{l}\text { Panic d, } \\
n=5\end{array}$ & $\begin{array}{l}\text { Somat, } \\
n=3\end{array}$ & $\begin{array}{l}\text { Omd, } \\
n=14\end{array}$ & $\begin{array}{l}\text { Hypo, } \\
n=I\end{array}$ & $\begin{array}{l}\text { Inso, } \\
\mathrm{n}=\mathbf{I}\end{array}$ \\
\hline Anemia, n (\%) & $38(22)$ & $13(25)$ & $19(35)$ & $8(24)$ & $5(26)$ & $8(32)$ & $2(40)$ & I (33) & $2(14)$ & $0(0)$ & $0(0)$ \\
\hline $\mathrm{Hb}(\mathrm{g} / \mathrm{dL})$ & 11.4 & 12.2 & II.I & 11.6 & 10.6 & 11.88 & 11.5 & 11.5 & 11.6 & 14.9 & 13.7 \\
\hline Htc (\%) & 34.4 & 34.8 & 33.7 & 34.5 & 34.2 & 32.8 & 34.25 & 36.1 & 35 & 46.6 & 40 \\
\hline $\operatorname{RBC}\left(10^{6} / \mathrm{mm}^{3}\right)$ & 4.14 & 4.12 & 4.07 & 4.14 & 4.17 & 4.3 & 4.3 & 4.23 & 4.16 & 5.35 & 4.4 \\
\hline RDW (\%) & 17.7 & 17.5 & 18.5 & 16.06 & 17.98 & 16.98 & 18.95 & 17.8 & 18.5 & 19.3 & 13 \\
\hline $\mathrm{MCV}(\mathrm{fL})$ & 75.6 & 72.9 & 72.3 & 76 & 75.3 & 78.5 & 79 & 91 & 69.5 & 87 & 89 \\
\hline
\end{tabular}

Abbreviations: Dep d, depressive disorder; Bip d, bipolar disorder; Psyc, psychotic disorder; Conv, conversion disorder; OCD, obsessive-compulsive disorder; Gad, generalized anxiety disorder; Panic d, panic disorder; Somat, somatoform disorder; Omd, other unidentified mood disorders; Hypo, hypochondriasis; Inso, insomnia; $\mathrm{Hb}$, hemoglobin; Htc, hematocrit; RBC, red blood cells; RDW, red blood cell distribution width; MCV, mean corpuscular volume. 
Table 4 Comparison of hematological parameters based on sex

\begin{tabular}{llllll}
\hline & $\begin{array}{l}\text { Mean values in } \\
\text { females }(\mathbf{n = 2 2 9})\end{array}$ & $\begin{array}{l}\text { Mean values in } \\
\text { males }(\mathbf{n = 1 4 9 )}\end{array}$ & P-value & $\begin{array}{l}\text { Min-Max values } \\
\text { in females }\end{array}$ & $\begin{array}{l}\text { Min-Max values } \\
\text { in males }\end{array}$ \\
\hline Anemia, $\mathrm{n}(\%)$ & $8 \mathrm{I}(35)$ & $15(\mathrm{I0})$ & $<0.001$ & - & - \\
$\mathrm{MCV}(\mathrm{fL})$ & $72.5 \pm 8.5$ & $83 \pm 15$ & 0.005 & $55-103$ & $64-105$ \\
$\mathrm{Hb}(\mathrm{g} / \mathrm{dL})$ & $11.2 \pm 0.98$ & $13.2 \pm 2.8$ & $<0.001$ & $8-12$ & $9.1-18.4$ \\
$\mathrm{Htc}(\%)$ & $34.2 \pm 3.4$ & $34.8 \pm 2.4$ & 0.54 & $24-56$ & $28.3-36.9$ \\
Age (year) & $4 I \pm 14$ & $41 \pm 16$ & 0.927 & $18-85$ & $18-90$ \\
RBC $\left(10 \% / \mathrm{mm}^{3}\right)$ & $4.1 \pm 0.43$ & $4.16 \pm 0.3$ & 0.784 & $3.1-8.4$ & $3.27-4.48$ \\
RDW\% & $17.9 \pm 2.2$ & $17.2 \pm 1.36$ & 0.208 & $16.1-20.5$ & $10-24.5$ \\
\hline
\end{tabular}

Note: Data are presented as mean \pm standard deviation.

Abbreviations: Min, minimum; Max, maximum; MCV, mean corpuscular volume; Hb, hemoglobin; Htc, hematocrit; RBC, red blood cells; RDW, red blood cell distribution width.

insufficient social support systems available to help with the follow-up and treatment of psychiatric patient group and since they could not benefit from treatment services effectively, the therapies they receive are deficient and inadequate. As a result of these factors and also since health professionals tend to prioritize their mental condition and ignore their physical complaints, the physical symptoms are usually passed over, and their preexisting psychiatric disorder aggravates. In a study conducted with medical students, low serum ferritin and $\mathrm{Hb}$ levels were indicated among students with depression. ${ }^{16}$ There are other studies in the literature that reported a relationship between $\mathrm{Hb}$ levels and depressive disorder and anxiety disorder. ${ }^{17,18}$

The prevalence of anemia in the depressive disorder patient group (22\%) was found to be higher than the general population in this study, parallel to the findings in the literature. ${ }^{13}$ It was determined in the study that $25 \%$ of bipolar patients suffered from anemia as well. Psychotropic drugs used for chronic psychiatric diseases cause significant hematological side effects, such as anemia, leukopenia, thrombocytopenia, and thrombocytosis. These side effects are observed more frequently in patients who use mood stabilizer drugs, such as lithium, clozapine, carbamazepine, valproic acid, and reuptake inhibitors. ${ }^{19}$ The reason for high anemia rates among bipolar patients in the study could be related to the long-term use of these mood stabilizer drugs.

In chronic psychiatric patients, the rate of existence of an accompanying physical disease in addition to the primary disorder is usually high. ${ }^{9}$ This coexistence deteriorates the quality of life of the patients, prolongs the psychiatric treatment period, and could even cause an increase in morbidity and mortality. Factors such as negligence of physical symptoms by mental health professionals, assessment of physical complaints as psychosomatic, reluctance of nonpsychiatrist physicians to provide services to psychiatric patients, lack of time and resources for checkups in mental health services, and inefficiency of patients in explaining their medical problems and difficulties related to implementing changes in lifestyle, could prevent psychiatric patients from receiving appropriate health care services. ${ }^{20}$ Treatmentrelated factors, drugs taken, physical conditions, negative lifestyle habits, and nutritional disorders are the reasons for anemia among chronic psychiatric patients. Detailed identification of the physical symptoms of psychiatric patients and providing health care services to them, who experience problems in expressing their complaints and are often labeled by the society, are quite important for early diagnosis and treatment.

\section{Results}

Prevalence of anemia observed among chronic psychiatric patients is higher than the mean prevalence in the general population. Thus, this study concludes that it would be beneficial for this group of patients for the health professionals to recognize the physical symptoms and provide the required examinations for anemia. Also, the findings of the study deemed especially important that the patients and caretakers should be informed about the necessity to change the negative lifestyles and malnutrition habits of the patients.

Table 5 Hemoglobin value distribution by age group

\begin{tabular}{|c|c|c|c|c|c|c|}
\hline & $\begin{array}{l}\text { I 8-24 years, } \\
n=68\end{array}$ & $\begin{array}{l}25-34 \text { years, } \\
n=79\end{array}$ & $\begin{array}{l}\begin{array}{l}35-44 \\
\text { years, }\end{array} \\
\mathrm{n}=95\end{array}$ & $\begin{array}{l}45-54 \text { years, } \\
n=67\end{array}$ & $\begin{array}{l}55-64 \text { years, } \\
n=36\end{array}$ & $\begin{array}{l}\text { Over } 65 \text { years, } \\
n=33\end{array}$ \\
\hline $\mathrm{Hb}(\mathrm{g} / \mathrm{dL})$ & 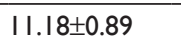 & $11.6 \pm 1.97$ & $11.64 \pm 1.5$ & $11.2 \pm 1.2$ & $11.5 \pm 0.8$ & $11.9 \pm 1.6$ \\
\hline
\end{tabular}

Note: Data are presented as mean \pm standard deviation.

Abbreviation: $\mathrm{Hb}$, hemoglobin. 


\section{Limitations}

The data were analyzed based on the information gathered from the records in the health automation system in this study. Thus, further parameters to help determine the type of anemia diagnosis were not available. Clinical psychiatric test results were also not available since face-to-face interviews with the patients were not possible.

\section{Disclosure}

The authors report no conflicts of interest in this work.

\section{References}

1. Johnson-Spear MA, Yip R. Hemoglobin difference between black and white women with comparable iron status: justification for race-specific anemia criteria. Am J Clin Nutr. 1994;60:117-121.

2. World Health Organization. Tech. Rep. Ser. 1968:405, Tech Rep. 1975:580.

3. Soysal T. Classification of anemia. In: Yazıcı H, Hamuryudan V, Sonsuz A. Cerrahpasa Internal medicine. İstanbul: İstanbul Medical Publishing; 2005;142-144.

4. Allen RP, Walters AS, Montplaisir J, et al. Restless legs syndrome prevalence and impact. REST General Population Study. Arch Intern Med. 2005;165:1286-1292.

5. Swanson JM, Kinsbourne M, Nigg J, et al. Etiological subtypes of attention deficit hyperactivity disorder: brain imaging, molecular genetics and environmental factors and the dopamine hypothesis. Neuropsychol Rev. 2007;17:39-59.

6. Stewart R, Hirani V. Relationship between depressive symptoms, ane$\mathrm{mia}$, and iron status in older residents from a national survey population. Psychosom Med. 2012;74:208-213.

7. Chen MH, Su TP, Chen YS, et al. Association between psychiatric disorders and iron deficiency anemia among children and adolescents: a nationwide population-based study. BMC Psychiatry. 2013;13:161.

8. Becker M, Axelrod DJ, Oyesanmi O, Markov DD, Kunkel EJ. Hematologic problems in psychosomatic medicine. Psychiatr Clin North Am. 2007;30:739-759.
9. Kısa C, Cebeci S, Uysal Z, Aydemir Ç, Göka E. Co-Occurring of physical illness in psychiatry inpatients. New Symp J. 2008;46:66-69.

10. American Psychiatric Association. Diagnostic and Statistical Manual of Mental Disorders. 4th ed. Washington, DC: American Psychiatric Association; 2000.

11. Karlıdağ Ç, Aksoy UM, Yüksel G, Alpay N, Uysal A. common medical problems in inpatient psychiatric care clinics. Klinik Psikiyatri. 2013; 16:47-52.

12. Leung MW, Xiong GL, Leamon MH, McCarron RM, Hales RE. General medical hospital admissions from a public inpatient psychiatric health facility: a review of medical complications over 30 months. Psychosomatics. 2010;51:498-502.

13. Eraslan E, Aydoğan E, Albayrak E, Denizli N. A comparison of the prevalence of iron deficiency anemia between adult women and men and between premenopausal and postmenopausal women. Yeni Tip Dergisi. 2011;28:109-112.

14. Carney CP, Jones L, Woolson RF. Medical comorbidity in women and men with schizophrenia a population-based controlled study. J Gen Intern Med. 2006;21:1133-1137.

15. Schoepf D, Uppal H, Potluri R, Heun R. Physical comorbidity and its relevance on mortality in schizophrenia: a naturalistic 12-year follow-up in general hospital admissions. Eur Arch Psychiatry Clin Neurosci. 2014; 264:3-28.

16. Vahdat Shariatpanaahi M, Vahdat Shariatpanaahi Z, Moshtaaghi M, Shahbaazi SH, Abadi A. The relationship between depression and serum ferritin level. Eur J Clin Nutr. 2007;61:532-535.

17. Lever-van Milligen BA, Vogelzangs N, Smit JH, Penninx BW. Hemoglobin levels in persons with depressive and/or anxiety disorders J Psychosom Res. 2014;76:317-321.

18. Onder G, Penninx BW, Cesari M, Bandinelli S, Lauretani F, Bartali B, et al. Anemia is associated with depression in older adults: results from the InCHIANTI study. J Gerontol A Biol Sci Med Sci. 2005;60: $1168-1172$.

19. Mazaira S. Haematological adverse effects caused by psychiatric drugs. Vertex. 2008;19:378-386.

20. Muir Cochrane E. Medical co-morbidity risk factors and barriers to care for people with schizophrenia. J Psychiatr Ment Health Nurs. 2006;13:447-452
Neuropsychiatric Disease and Treatment

\section{Publish your work in this journal}

Neuropsychiatric Disease and Treatment is an international, peerreviewed journal of clinical therapeutics and pharmacology focusing on concise rapid reporting of clinical or pre-clinical studies on a range of neuropsychiatric and neurological disorders. This journal is indexed on PubMed Central, the 'PsycINFO' database and CAS,

\section{Dovepress}

and is the official journal of The International Neuropsychiatric Association (INA). The manuscript management system is completely online and includes a very quick and fair peer-review system, which is all easy to use. Visit http://www.dovepress.com/testimonials.php to read real quotes from published authors. 